\title{
ASSESSMENT OF ANTIOXIDANT PROPERTIES OF EARLY-FLOWERING PLANTS
}

\author{
Balaeva-Tichomirova Olga*, Leonovich Evgenia
}

Vitebsk State University named after P.M. Masherov, Vitebsk, Belarus

\section{ОЦЕНКА АНТИОКСИДАНТНЫХ СВОЙСТВ РАННЕЦВЕТУЩИХ РАСТЕНИЙ}

\section{Балаева-Тихомирова Ольга , Леонович Евгения}

\author{
Received 26. 6. 2017 \\ Revised 28.6. 2017 \\ Published 24. 11. 2017
}

In connection with the increase in the impact of unfavorable environmental factors on biological objects, including plants used in agriculture, it is important to find adequate ways to counteract current stressors (climate change - extreme temperature effects, drought and excessive watering of soils, accumulation of heavy metals and other). Among the factors that counteract stress, natural biocompatible biologically active compositions containing endogenous antioxidants are of great interest. The aim of the study was to justify the possibility of using primroses as a biosubstance containing endogenous antioxidants to reduce and prevent the effects of oxidative stress. The object of the study were early-flowering plants - Allium ursinum L., Primula véris L., Állium schoenoprásum L. In the primrose leaves, the content of endogenous antioxidants (diene conjugates, the sum of flavonoids, the sum of phenolic compounds, ascorbic acid), the activity of the antioxidant system (the content of lipid peroxidation products, diene conjugates) was determined. The investigated parameters were determined by the spectrophotometric method. Results of the study. Analyzing the changes in antioxidant activity of early flowering plants, it has been established that they are characteristics of structural-functional adaptations and vary insignificantly depending on the place and conditions of growth and the type of plant population, which makes it possible to cultivate them without loss of value characteristics as an antioxidant biosubstance and conservation of biodiversity of protected natural populations. The results of the study can be used to create from primrose extracts possessing antioxidant effect, which are affordable and simple in their implementation and the ability to further process biological objects with this substrate, increasing their stress resistance to unfavorable factors.

Keywords: early-flowering plants; biosubstances; endogenous antioxidants; indicators of non-enzymatic antioxidant system; oxidative stress

\section{Введение}

Стрессоры при воздействии на биологические объекты формируют неспецифичную ответную реакцию, во многом определяемую либо избыточностью прооксидантных процессов, либо недостаточностью существующих эндогенных антиоксидантных систем. Обработка биологического объекта биосовместимым природным антиоксидантным поликомпонентным препаратом может повысить устойчивость его к действию факторов, вызывающих окислительный стресс или снизить последствия данного воздействия. В качестве сырья для

\footnotetext{
*Corresponding author: Olga Balaeva-Tichomirova, Vitebsk State University named after P.M. Masherov,
} Vitebsk, Belarus, $\bowtie$ olgabal.tih@gmail.com 
таких антиоксидантных экстрактов предполагается использовать биомассу раннецветущих растений, для этого необходимо исследовать содержание эндогенных антиоксидантов, содержащихся в раннецветущих растениях (Веретенников, 2006).

Цель работы - обосновать возможность использования первоцветов в качестве биосубстанции содержащей эндогенные антиоксиданты для снижения и предупреждения последствий окислительного стресса.

\section{Материалы и методы}

Объект исследования - раннецветущие растения - лук медвежий (Allium ursinum L.); первоцвет весенний (Primula véris L.); лук шнитт (Állium schoenoprásum L.).

Предмет исследования - содержание эндогенных антиоксидантов (суммы флавоноидов, суммы фенольных соединений, аскорбиновой кислоты), активность антиоксидантной системы (содержание продуктов перекисного окисления липидов, диеновых коньюгатов).

Исследуемые показатели определялись спектрофотометрическим методом.

Содержание диеновых конъюгатов определялось в суспензии хлоропластов, растворяя их в смеси гептан: изопропиловый спирт в соотношении 1 : 1 (Ермаков, 1987). Концентрация продуктов перекисного окисления липидов устанавливалась по тесту с тиобарбитуровой кислотой (Либберт, 1976). Содержание суммы фенольных соединений определялось в спиртовых экстрактах при добавлении реактива Фолина-Чиокальтеу (Веретенников, 2006). Содержание суммы флавоноидов выявлялось в спиртовых экстрактах при добавлении раствора алюминия хлорида (Гребинский, 2005).

Математическую обработку полученных результатов проводили методами параметрической и непараметрической статистики с использованием пакета статистических программ Microsoft Excel 2003, STATISTICA 6.0. Достоверность различий учитывали при $p<0,05$.

\section{Результаты и их обсуждение}

Раннецветущие растения на всех стадиях развития устойчивы к климатическому стрессу (низкой температуре, влажности воздуха и почвы в начале вегетации, значительных перепадах ночных и дневных температур воздуха и почвы, к постоянным северо-западным ветрам). Первоцветы обладают высокой способностью к биологической адаптации, что необходимо для их нормального функционирования под воздействием экстремальных условий. Сложные условия произрастания приводят к активации окислительного стресса и увеличению числа свободных радикалов, что может привести к гибели клеток и как следствие гибели самого растения.

Установлено, что эндогенные вещества растения способны нейтрализовать избыточное образование свободных радикалов, проявляя тем самым защитные, антиоксидантные свойства. Выявлено, что способностью к «тушению» реакций одноэлектронного восстановления кислорода обладают такие соединениями, как аскорбиновая кислота, токоферол, восстановленный глутатион, флавоноиды, полифенольные комплексы, полиамины, свободные аминокислоты (в частности, пролин), растворимые углеводы.

Ферменты-антиоксиданты катализируют преимущественно реакции нейтрализующие супероксид и перекись водорода, а детоксикация реактивных производных кислорода (синглетный кислород, гидроперекисный радикал, гидроксил-радикал и пероксинитрит) осуществляется эндогенными антиоксидантными относящимися к неферментативной антниоксидантной системе растения.

Фенольные соединения участвуют в окислительно-восстановительных процессах, защитных механизмах, в процессах роста растения, являются антиоксидантами и стимулируют деление клеток. Наибольшее содержание фенольных соединений зафиксировано в листьях первоцвета весеннего природной популяции, произрастающей в лесничестве Борисовского 
района, и составляет 50,32 мг/г. Наименьшее значение данного показателя отмечено в листьях лука медвежьего природной популяции, произрастающего в лесничестве Витебского района и составляет 14,26 мг/г, что в 3,53 раза меньше, чем в листьях первоцвета весеннего. Значение данного показателя внутри популяции одного вида варьируют незначительно и составляет у первоцвета весеннего $\Delta 1,01 \mathrm{Mr} / \mathrm{r}$, у медвежьего лука - $\Delta 1,12 \mathrm{mr} / \mathrm{r}$, у лука шнитт $\Delta$ 1,68 мг/г. Выявлено, что содержание данного показателя статистически значимо отличается между растениями, произрастающими в г. Витебске и Витебском районе и растениями из Борисовского района, что может быть связано с более северным местом расположения популяций и большему климатическому стрессу (табл. 1).

Таблица 1 Содержание эндогенных антиоксидантов и активность антиоксидантной системы листьев природных и интродуционных популяций раннецветущих растений $(\mathrm{M} \pm \mathrm{m})$

Table 1 The content of endogenous antioxidants and the activity of the antioxidant system of leaves of natural and introductive populations early-flowering plants $(M \pm m)$

\begin{tabular}{|c|c|c|c|}
\hline \multirow[t]{2}{*}{ Растительный объект } & \multicolumn{3}{|c|}{ Место сбора } \\
\hline & $\begin{array}{c}\text { Ботанический сад } \\
\text { (г. Витебск) }\end{array}$ & $\begin{array}{c}\text { Лесничество } \\
\text { (Борисовский р-н) }\end{array}$ & $\begin{array}{c}\text { Лесничество } \\
\text { (Витебский р-н) }\end{array}$ \\
\hline \multicolumn{4}{|c|}{ Диеновые конъюгаты (мкмоль/г) } \\
\hline Allium ursinum & $0,54 \pm 0,03$ & $0,49 \pm 0,07^{1}$ & $0,54 \pm 0,03^{1}$ \\
\hline Primula véris & $0,74 \pm 0,01^{1-3}$ & $0,81 \pm 0,05^{1-3}$ & $0,84 \pm 0,14^{1-3}$ \\
\hline Állium schoenoprásum & $0,45 \pm 0,02^{1-3}$ & $0,41 \pm 0,03^{1-3}$ & $0,21 \pm 0,02^{1-3}$ \\
\hline \multicolumn{4}{|c|}{ Продукты перекисного окисления липидов (нмоль/г) } \\
\hline Allium ursinum & $8,49 \pm 0,20$ & $4,56 \pm 0,79^{1}$ & $7,18 \pm 1,02^{1}$ \\
\hline Primula véris & $4,51 \pm 0,17^{1-3}$ & $5,10 \pm 0,82^{1-3}$ & $4,57 \pm 0,36^{1-3}$ \\
\hline Állium schoenoprásum & $2,62 \pm 0,45^{1-3}$ & $3,30 \pm 0,59^{1-3}$ & $2,77 \pm 0,32^{1-3}$ \\
\hline \multicolumn{4}{|c|}{ Сумма фенольных соединений (мг/г) } \\
\hline Allium ursinum & $22,99 \pm 3,73$ & $20,60 \pm 2,70^{1}$ & $14,26 \pm 4,79^{1}$ \\
\hline Primula véris & $49,62 \pm 4,80^{1-3}$ & $50,32 \pm 2,08^{1-3}$ & $49,67 \pm 2,07^{1-3}$ \\
\hline Állium schoenoprásum & $15,39 \pm 2,01^{1-3}$ & $19,76 \pm 1,29^{1-3}$ & $18,08 \pm 3,35^{1-3}$ \\
\hline \multicolumn{4}{|c|}{ Сумма флавоноидов (мг/г) } \\
\hline Allium ursinum & $1,83 \pm 0,66$ & $1,76 \pm 0,60^{1}$ & $1,09 \pm 0,23^{1}$ \\
\hline Primula véris & $2,28 \pm 0,28^{1-3}$ & $2,01 \pm 0,38^{1-3}$ & $2,21 \pm 0,44^{1-3}$ \\
\hline Állium schoenoprásum & $1,23 \pm 0,17^{1-3}$ & $1,16 \pm 0,10^{1-3}$ & $1,21 \pm 0,11^{1-3}$ \\
\hline \multicolumn{4}{|c|}{ Аскорбиновая кислота (мг/г) } \\
\hline Allium ursinum & $23,59 \pm 0,221$ & $18,96 \pm 0,313^{1}$ & $16,72 \pm 0,411^{1}$ \\
\hline Primula véris & $77,43 \pm 0,54^{1-3}$ & $81,65 \pm 0,73^{1-3}$ & $78,32 \pm 0,62^{1-3}$ \\
\hline Állium schoenoprásum & $11,65 \pm 0,15^{1-3}$ & $10,22 \pm 0,13^{1-3}$ & $10,06 \pm 0,11^{1-3}$ \\
\hline
\end{tabular}


Флавоноиды защищают растительные ткани от избыточной радиации, обладают противовоспалительным, антиоксидантным действием, участвуют в окислительновосстановительных реакциях, протекающих в растительных тканях, нейтрализуя избыток свободных радикалов.

Наибольшее содержание суммы флаваноидов зафиксировано в листьях первоцвета весеннего интродукционной популяции, произрастающей в ботаническом саду г. Витебска, и составляет 2,28 мг/г. Наименьшее значение данного показателя отмечено в листьях лука медвежьего природной популяции, произрастающего в лесничестве Витебского района и составляет 1,09 мг/г, что в 2,1 раза меньше, чем в листьях первоцвета весеннего.

Отмечено, что содержание суммы флаваноидов статистически значимо отличаются В зависимости от местопроизрастания, но изменения значений данного показателя варьируют незначительно. Так, например, у медвежьего лука при сравнении с растениями из лесничества Витебского района содержание суммы флаваноидов в 1,68 раз и 1,61 раза больше в популяциях ботанического сада и лесничества Борисовского района соответственно. Данный показатель изменяется незначительно в пределах одного вида, мг/г: у первоцвета весеннего на $\Delta 0,27$, у медвежьего лука $-\Delta 0,76$, у лука шнитт - $\Delta 0,07$.

Аскорбиновая кислота является важнейшим внутриклеточным антиоксидантом, способным легко отдавать два атома водорода, используемых в реакциях обезвреживания свободных радикалов. Наибольшее содержание аскорбиновой кислоты зафиксировано в листьях первоцвета весеннего, произрастающего в природной популяции в лесничестве Борисовского района и составляет 81,65 мг/г. Наименьшее значение данного показателя отмечено в листьях лука шнитт природной популяции, произрастающего в лесничестве Витебского района и составляет 10,06 мг/г, что в 8,12 раза меньше, чем в листьях первоцвета весеннего. Отмечено, что разница в содержании витамина С между видами растений значительная и отличается в 4,32 раза и 7,99 раз при сравнении содержания в листьях первоцвета весеннего с медвежьем луком и луком шнитт соответственно, и при сравнении - между медвежьем луком и луком шнитт в 1,86 раз. У одного вида растения в зависимости от местообитания показатель изменяется незначительно, например у медвежьего лука содержание витамина С в 1,41 раз и 1,25 раза больше в популяциях ботанического сада г. Витебска и Борисовского района соответственно при сравнении с растениями из популяции лесничества Витебского района.

Для оценки возможности данного растения противостоять неблагоприятным факторам окружающей среды, помимо содержания эндогенных антиоксидантов, используют активность антиоксидантной системы, которую оценивают по содержанию промежуточных и конечных продуктов перекисного окисления липидов. Наибольшее содержание диеновых коньюгатов выявлено в листьях первоцвета весеннего, произрастающего в природной популяции лесничестве Витебского района и составляет 0,84 мкмоль/г, наименьшее значение 0,21 мкмоль/г в листьях лука шнитт того же местопроизрастания, что в 4 раза меньше чем в листьях первоцвета весеннего. Установлено, что разница в содержании диеновых коньюгатов между видами растений значительная и отличается в 1,56 раза и 4 раза при сравнении содержания в листьях первоцвета весеннего с медвежьем луком и луком шнитт соответственно, и при сравнении между медвежьем луком и луком шнитт - в 2,57 раза. При сопоставлении данных по одному виду в зависимости от местопроизрастания и типа популяции значительных изменений не отмечено. Наибольшие отличия выявлены у лука шнитт, которые составляют при сравнении природной популяцией Витебского лесничества с интродуционной популяцией ботанического сада г. Витебска 2,14 раза и 1,95 раза-сприродной популяцией Борисовского района.

Наибольшее содержание продуктов перекисного окисления липидов зафиксировано в листьях медвежьего лука, произрастающего в Ботаническом саду г. Витебска. Отмечено, что данный показатель выше у медвежьего лука в 1,9 раза по сравнению с первоцветом и в 
3,2 раза по сравнению с луком шнитт. В зависимости от местообитания данный показатель изменяется незначительно, но у медвежьего лука повышен в популяциях ботанического сада г. Витебска и лесничества Витебского района в 1,86 и в 1,57 соответственно при сравнении показателя с популяцией лесничества Борисовского района.

Активность антиоксидантной системы выше в популяциях ботанического сада г. Витебска и лесничества Витебского района, что связано с тем, что данные местопроизрастания видов находятся севернее на карте Республики Беларусь, где усиливаются потоки холодного северо-западного ветра, увеличиваются колебания температур воздуха и почвы, и как следствие повышается количество свободных радикалов и необходимость в их утилизации.

Таким образом, по содержанию эндогенных антиоксидантов наибольшей антиоксидантной активностью и возможностью противодействовать последствиям окислительного стресса обладают листья первоцвета и медвежьего лука не зависимо от типа популяции и местопроизрастания.

Лук шнитт обладает достаточным запасом антиоксидантных соединений и активностью антиоксидантной системы, но уступает по всем показателям первоцвету весеннему и медвежьему луку, что доказывается данными таблицы 1, наибольшее содержание суммы фенольных соединений, суммы флавоноидов, аскорбиновой кислоты отмечено в листьях первоцвета весеннего. Активность перекисного окисления липидов снижена в листьях первоцвета весеннего по сравнению с медвежьим луком в 1,9 раза. По сравнению с медвежьем луком в первоцвете весеннем увеличено содержание следующих показателей: сумма фенольных соединений - в 2,16 раза, сумма флавоноидов - в 1,25 раза, аскорбиновой кислоты в 3,28 раза. По сравнению с луком шнитт в первоцвете весеннем увеличено содержание следующих показателей: суммы фенольных соединений - в 3,2 раза, суммы флавоноидов в 1,9 раза, аскорбиновой кислоты - в 6,6 раза.

\section{Выводы}

Таким образом, биомасса первоцветов может быть использована для изготовления экстрактов, обладающих антиоксидантным действием, которые являются доступными по цене и простыми по своей реализации и возможностью в дальнейшем обрабатывать биологические объекты данным субстратом, увеличивая их стрессоустойчивость к неблагоприятным факторам.

Проанализировав изменения показателей антиоксидантной активности раннецветущих растений, установлено, что они являются характеристиками структурнофункциональных адаптаций и варьируют незначительно в зависимости от места и условий произрастания и типа популяции растений, что дает возможность их культивирования без потери ценностных характеристик как антиоксидантной биосубстанции и сохранения биоразнообразия охраняемых природных популяций.

\section{Литература}

Ercisl, S., Orhan, E., Ozdemir, O., Sengul, M. 2008. Seasonal variation of total phenolic, antioxidant activity, plant nutritional elements, and fatty acids in tea leaves (Camellia sinensis var. sinensis clone Derepazari) grown in Turkey. Pharmaceutical Biology, vol. 46, no. 10-11, pp. 683-687. DOI: 10.1080/13880200802215818

Kothari, V., Seshadri, S. 2010. Antioxidant activity of seed extracts of Annona squamosa and Carica papaya. Nutrition and Food Science, vol. 40, no. 4, p. 403-408. DOI: 10.1108/00346651011062050

Kuntorini, E.M., Dewi, M. 2016. Anatomical structure and antioxidant activity of red bulb plant (Eleutherine americana) on different plant age. Biodiversitas, p. 229-233. DOI: 10.13057/biodiv/d170123

Charles, Denys, J. 2013. Antioxidant properties of spices, herbs and other sources. Springer Science + Business Media New York, 610 p. ISBN 978-1-4614-4309-4. 